\title{
Effect of rootstocks or interstems on dry matter allocation
}

\section{in apple}

\author{
Haishan An ${ }^{\mathrm{a}}$, Feixiong Luo ${ }^{\mathrm{a}}$, Ting Wu, Yi Wang, Xuefeng Xu, Xinzhong Zhang and Zhenhai Han \\ Institute for Horticultural Plants, College of Horticulture, China Agricultural University, Beijing, P.R. China
}

\begin{abstract}
Summary
Rootstocks, particularly dwarfing rootstocks, can affect their scions in many ways, such as altering photosynthetic capability and the pattern of dry matter allocation between rootstocks and graft units. Here, we investigated the potential dwarfing effect, net photosynthesis rate (Pn), and dry matter distribution in 'Red Fuji' (RF) scions growing on five different rootstocks/interstems. The results indicated that Pn in RF scions on the standard RF/BC rootstock was slightly higher than on the dwarfing rootstocks $\mathrm{RF} / \mathrm{M9}$ and RF/SH40, although the differences were not significant. Total leaf area of trees on RF/M9 and $\mathrm{RF} / \mathrm{SH} 40$ rootstocks were markedly lower than on the RF/BC rootstock. When M9 and SH40 were used as interstems, the trees had a reduced total leaf area but showed no differences in photosynthetic capacity. A larger proportion of photosynthates was allocated to fruit in trees on the dwarfing RF/M9 and RF/SH40 rootstocks than on the standard $\mathrm{RF} / \mathrm{BC}$ rootstock. In conclusion, the lower accumulation of photosynthates in trees on dwarfing rootstocks might be attributed to reduced leaf numbers or smaller total leaf areas, and photosynthesis did not appear to be influenced by the dwarfing effect of rootstocks or interstems.
\end{abstract}

Keywords

dry matter, dwarfing effect, interstems, Malus domestica Borkh., rootstocks

\section{Introduction}

Dwarfing rootstocks have been widely used in the apple industry for a long time because they can reduce vegetative growth, increase yield, and foster precocity in scions (Webster, 1995; Samad et al., 1999; Fallahi et al., 2002). Fruit on apple trees on dwarfing rootstocks show improved skin coloring, flesh firmness, and flavor (Drake et al., 1991). Although considerable research into the causes of the dwarfing effect has been carried out, the mechanisms remain poorly understood (Robinson et al., 2006).

It has been suggested that use of a dwarfing rootstock might affect the photosynthesis rate (Pn) of the scion. For example, Fallahi et al. (2001) reported that net Pn of shoot leaves of field-planted apple trees grafted on the dwarfing rootstock B9 is lower than shoot leaves of trees grafted on the more vigorous rootstocks Ottawa 3 and M7. However, shoot and spur leaves of field-planted trees on the dwarfing rootstock M9 have higher net Pn than those on M7 (Fallahi

a) These authors contributed equally to this work.

\section{Significance of this study}

What is already known on this subject?

- Complex interactions between rootstocks/interstems and scions may affect the rate of photosynthesis and influence growth and yield of apple trees.

What are the new findings?

- Dwarfing or standard rootstocks did not affect the rate of photosynthesis but did influence the leaf-area index and photosynthate allocation.

What is the expected impact on horticulture?

- The results aid our understanding of the dwarfing effect of dwarf rootstocks, and will facilitate the selection of rootstocks during cultivation practice.

et al., 2002). Interestingly, there is no significant difference between shoot leaf Pn of potted trees grafted on dwarfing rootstocks and those of trees on vigorous rootstocks (Barden and Ferree, 1979). These inconsistent findings may result from the use of trees of different ages, differences in sampling methods, or variations between the years in which the experiments were performed. Nevertheless, these results also imply that the photosynthetic rate is not likely to cause the dwarfing effect (Inomata et al., 2005). In addition, Pn can also be affected by the compatibility of the rootstock/ interstem and the graft unions. Generally, lower Pn is found in incompatible unions (Ferree, 1992; Rieger, 1992; Ferree et al., 1996). Losciale et al. (2008) found that both stomatal conductance and transpiration were consistently higher in trees grafted on a compatible union compared to those on an incompatible union; these differences resulted in greater photosynthetic efficiency in the trees on the compatible union. These observations suggest a relationship between photosynthetic potential and graft compatibility.

Another possible dwarfing mechanism is the altered distribution of photosynthates. The relative weight of fruit in proportion to trunks and branches (dry weight) of trees growing on the dwarfing rootstock M9 was estimated as 13.7 compared to 4.7 on the vigorous rootstock M16 (Preston, 1968). Additionally, on dwarfing rootstocks, more dry matter is allocated to reproductive parts, such as fruit, spurs, and spur leaves than to vegetative components, such as branches (Strong and Azarenko, 2000). On the very vigorous MM111 rootstock, approximately $51 \%$ more dry matter is present in the root system compared to trees on less vigorous rootstocks such as M9, M26, and M7a (Stutte et al., 1994).

Dwarfing rootstocks affect root production of composite apple trees. A comparison of root numbers indicated that trees growing on dwarfing rootstock M9 had approximately 
$34 \%$ of the root number of trees growing on the vigorous M7 rootstock (Neilsen et al., 1997). The dry weights of the root systems of trees on the dwarfing M9 rootstock were lower than those from the semi-dwarfing rootstocks MM106 and M793 (Hooijdonk et al., 2011). Root length densities of apple trees grafted on semi-dwarfing or semi-vigorous rootstocks are higher than those growing on dwarfing rootstocks (De Silva et al., 1999; Ma et al., 2013; An et al., 2017). Moreover, rootstocks also influence the root lifespan (Yao et al., 2006). Thus, the longevity of fine roots of trees on the dwarfing rootstocks Red Fuji/M9 and Red Fuji/SH40 was shorter than that of trees on the standard Red Fuji/Baleng Crab rootstock (Hou et al., 2012).

Trees on dwarfing rootstocks tend to have lower numbers of leaves and thus have a smaller total leaf area. Reduction in total leaf area is found in trees on most dwarfing rootstocks such as M9 (dwarfing), M27 (very dwarfing), and MM106 (semi-dwarfing) (Webster, 1995). To date, however, little is known about how dwarfing rootstocks bring about these differences. The objective of the present study was to determine the rate of photosynthesis, dry matter allocation, and performance of aboveground traits in trees on different apple dwarfing rootstocks or interstems. Furthermore, the contribution of these various factors to the underlying dwarfing mechanism of the rootstock was analyzed.

\section{Materials and methods}

\section{Site description and facilities}

Ten rhizo-pits [1.5 × $1.5 \times 3.0 \mathrm{~m}$ (length $\times$ width $\times$ height) $]$ were constructed in a greenhouse. These rhizo-pits were made of reinforced concrete with an open top. Eight holes were made in the base of each rhizo-pit to drain away excess water after irrigation. Five layers of horizontal minirhizotron tubes $(178 \mathrm{~cm}$ in length and $5.6 \mathrm{~cm}$ in diameter) were installed before the rhizo-pits were filled with a growing sub- strate composed of garden soil, peat, and vermiculite (3:1:1 in volume). The distances between the five tube layers and the ground were 20,60,100, 150, and $200 \mathrm{~cm}$. Each layer contained four symmetrically placed tubes (as shown in Figure 1). The materials were planted in the spring of 2009. In this paper, the plants were described as scion/rootstock or scion/interstem/rootstock combinations. Five rootstocks/ interstems were used in the study, with two replicates for each type of tree. The scion cultivar was 'Red Fuji' (RF). The grafted complexes were RF/M9 (dwarfing), RF/Shao series no. 40 (RF/SH40, dwarfing), RF/Baleng Crab (RF/BC, standard), RF/M9/BC (dwarfing interstem) and RF/SH40/BC (dwarfing interstem); the length of the interstem was $25 \mathrm{~cm}$ in all cases (Ma et al., 2013). The experimental design, installation of minirhizotron tubes for fine root observation, preparation of the growing substrate, and plant cultivation management have been described in detail previously (Hou et al., 2012; Ma et al., 2013).

The trees were trained as slender spindles. The temperature in the greenhouse was maintained at $15-25^{\circ} \mathrm{C} / 10-20^{\circ} \mathrm{C}$ (day/night) during the growing season (from May to November) and at $5-15^{\circ} \mathrm{C}$ during dormancy (from December to April of the next year). Drip irrigation was used for daily water management. The irrigation interval during the summer (from June to August) was two weeks; at other seasons, a three-week interval was used. Approximately $80 \mathrm{~L}$ of water was applied to each rhizo-pit during each irrigation interval.

\section{Photosynthesis and leaf area measurements}

Five fully expanded leaves (the $5^{\text {th }}-6^{\text {th }}$ functional leaf from growth point) from new shoots that were exposed to full direct sunlight were sampled randomly for net photosynthesis rate $(\mathrm{Pn})$ measurement from each tree. The Pn was measured using a LI-6400 portable photosynthesis system (LI-6400XT, LI-COR Inc., Lincoln, NE, USA) between 9:00 am to $11: 00$ am on sunny days from June to July with a 10-day

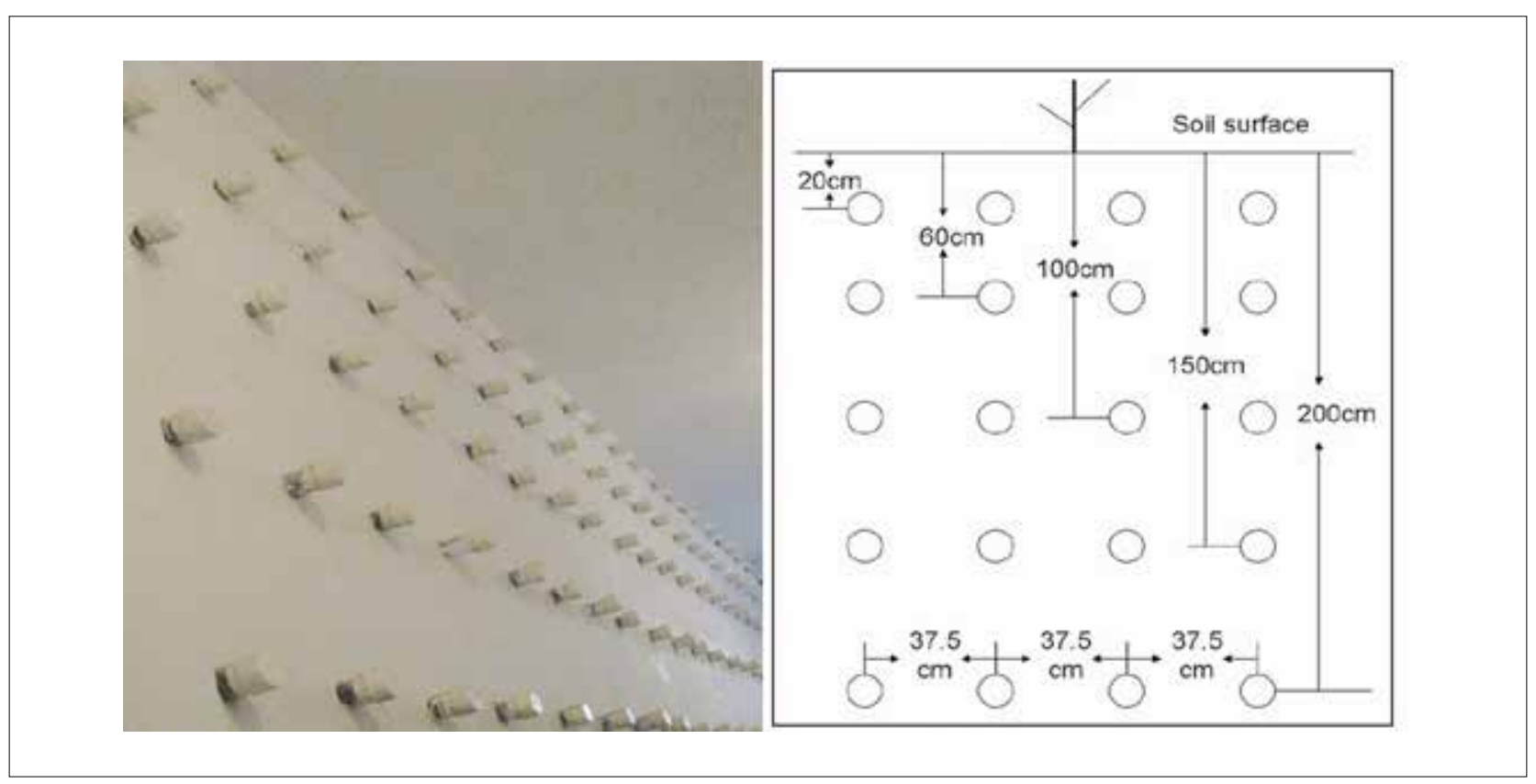

FIGURE 1. Schematic diagram of rhizo-pits and distribution of minirhizotron tubes. Left: The belowground part of rhizo-pits; Right: Schematic diagrams and their distribution of minirhizotron tubes. The circles present the installed minirhizotron tubes. Five layers of minirhizotron tubes were installed horizontally in the rhizo-pit at $-20,-60,-100,-150$ and $-200 \mathrm{~cm}$ from soil surface, respectively. Each layer contained four tubes (total 20 tubes for each rhizo-pit) that were fixed along the same layer symmetrically and parallel to each other with $37.5 \mathrm{~cm}$ between the tubes. 
interval. Each leaf was measured three times. All measurements were performed under the following environmental conditions: $1,200 \mu \mathrm{mol} \mathrm{m} \mathrm{m}^{-2} \mathrm{~s}^{-1}$ photosynthetic photon flux, $65 \pm 5 \%$ relative humidity, $25 \pm 2{ }^{\circ} \mathrm{C}$ leaf temperature, and $400 \mu \mathrm{mol} \mathrm{mol}{ }^{-1} \mathrm{CO}_{2}$ concentration. The leaf areas of 20 leaves from each tree were scanned in situ with a Li-3000C portable leaf area meter (LI-3000C, LI-COR, Inc., Lincoln, NE, USA).

\section{Measurement of aboveground traits}

Ten apples on each tree were randomly selected and their lengths and diameters were measured using an electronic digital caliper. They were measured from 30 days after full bloom until ripening, at intervals of 10 days. The yield efficiency of each graft combination was described in detail in An et al. (2017); the trees in this study were not subjected to fruit thinning. Tree trunk diameter was measured at $10 \mathrm{~cm}$ above the graft union and the trunk cross-sectional area (TCSA) was calculated. Ten new shoots, five each from the west and east side of the tree, were randomly labeled, and the shoots was measured at 10-day intervals until the cessation of elongation. The relative growth rate of shoots (RGRS) was estimated as: RGRS = average shoot length/TCSA. The number of shoots was counted after leaf fall without any pruning (pruning of each tree was performed before bud-breaks in each year). For each tree, 10 shoots and spurs were selected and the number of leaves was counted every 10 days.

\section{Dry matter of fruit, leaves, and fine roots}

The fresh weight of the fruit was determined using electronic digital scales after harvest. Ten apples were selected from each tree to measure relative water contents. The selected fruits were sliced into pieces and dried in an oven at $80^{\circ} \mathrm{C}$ to a constant weight. To estimate leaf dry matter volume, 300 leaves were harvested randomly as rootstock does not affect specific leaf weight (Barden and Ferree, 1979). The leaves were dried at $105^{\circ} \mathrm{C}$ for $20 \mathrm{~min}$ to inactivate enzymes and then at $80^{\circ} \mathrm{C}$ to a constant weight. Fine root dry matter was determined using the formula:

$$
W=0.634+0.7689 S_{\text {area }}
$$

where $S_{\text {area }}$ is the total surface area of annually produced fine roots ( $\leq 2 \mathrm{~mm}$ in diameter) (Wu et al., 2012). The fine roots were monitored in the minirhizotrons using the ET100 Root Observation System (Bartz Technology Corp., Santa Barbara, CA, USA), and the surface area of individual fine roots was automatically processed using WinRHIZO Tron MF (Regent 177 Instruments Inc., Quebec, Canada).

\section{Data processing}

All data were statistically analyzed using one-way analysis of variance (ANOVA) with SPSS 18.0 (SPSS Inc., Chicago, USA). Duncan's multiple range test was used to compare differences among treatments. The graphic was created by SigmaPlot 10.0 (Standford, CA, USA).

\section{Results}

\section{Photosynthesis rate, leaf area, and dry matter accumulation}

The rootstocks/interstems did not affect photosynthesis (Pn) in scions. In 2012, the average net Pn of RF/SH40 and $\mathrm{RF} / \mathrm{SH} 40 / \mathrm{BC}$ was higher than that of trees on RF/M9, RF/ $\mathrm{BC}$ and $\mathrm{RF} / \mathrm{M} 9 / \mathrm{BC}$, although the differences were not significant (Figure 2). In 2013-2015, dwarfing rootstock RF/M9 had the lowest Pn; the Pn of standard rootstock RF/BC was slightly higher than those of the four other graft combinations, although no significant differences in Pn were detected between dwarfing and standard rootstocks (Figure 2).

The total leaf areas of the RF/BC and RF/SH40/BC combinations were clearly larger than those of RF/M9 and RF/ SH40 in 2012 (Figure 3). There were no significant differences in total leaf areas among $\mathrm{RF} / \mathrm{BC}, \mathrm{RF} / \mathrm{M} 9 / \mathrm{BC}$ and $\mathrm{RF} /$ SH40/BC or among RF/M9, RF/SH40 and RF/M9/BC in 2012 (Figure 3). During 2013-2015, the total leaf areas of RF/BC and $\mathrm{RF} / \mathrm{M} 9 / \mathrm{BC}$ were significantly larger than those of RF/ SH40; there was no significant difference among RF/M9, RF/ $\mathrm{SH} 40$ and RF/SH40/BC or among RF/M9, RF/BC, RF/M9/BC and RF/SH40/BC (Figure 3).

The accumulation of daily photosynthates in $\mathrm{RF} / \mathrm{BC}$ and $\mathrm{RF} / \mathrm{SH} 40 / \mathrm{BC}$ was significantly greater than in RF/M9 and $\mathrm{RF} / \mathrm{SH} 40$; no significant difference in photosynthate accumulation was detected in 2012 among RF/BC, RF/M9/BC and RF/SH40/BC, or among RF/M9, RF/SH40 and RF/M9/ BC (Figure 4). During 2013-2014, photosynthate accumulation in $\mathrm{RF} / \mathrm{BC}$ and $\mathrm{RF} / \mathrm{M} 9 / \mathrm{BC}$ was significantly higher than that of RF/SH40; there were no differences among RF/M9, $\mathrm{RF} / \mathrm{SH} 40$ and RF/SH40/BC (Figure 4). The photosynthate accumulation of $\mathrm{RF} / \mathrm{BC}$ and $\mathrm{RF} / \mathrm{M} 9 / \mathrm{BC}$ was nearly twice as high as that of RF/M9 and RF/SH40/BC, but the differences among RF/M9, RF/BC, RF/M9/BC, RF/SH40/BC were not significant (Figure 4). In 2015, photosynthate accumulation in $\mathrm{RF} / \mathrm{M} 9 / \mathrm{BC}$ was significantly higher than in RF/M9 and $\mathrm{RF} / \mathrm{SH} 40$; there were no statistically significant differences among RF/BC, RF/M9/BC and RF/SH40/BC. Photosynthate accumulation levels in $\mathrm{RF} / \mathrm{BC}$ and $\mathrm{RF} / \mathrm{SH} 40 / \mathrm{BC}$ were almost twice as high as those of RF/M9 and RF/SH40, whereas the difference among RF/M9, RF/SH40, RF/BC, and RF/SH40/ $\mathrm{BC}$ was not significant (Figure 4).

\section{Annual dry matter distribution}

The annual total dry matter differed among years. In 2012, 2013, and 2015, total dry matter from RF/M9 and RF/ SH40 was significantly lower than from RF/BC. In 2014, the difference between RF/M9 and RF/BC was not significant (Table 1). There was no difference in annual total dry matter between RF/BC and RF/M9/BC during 2012-2015, while total dry matter of RF/SH40/BC changed considerably between years (Table 1 ).

The addition of the dwarfing interstem SH40 (i.e., RF/ SH40/BC) increased fruit dry matter throughout the trial in comparison with other combinations, except in 2014 (Table 1). Standard rootstock RF/BC had the least fruit dry matter in all tested years. However, the leaf dry matter of RF/ $\mathrm{BC}$ was significantly greater than those of dwarfing rootstock $\mathrm{RF} / \mathrm{M} 9$ and RF/SH40 in the whole trial (Table 1). There were no significant differences in the leaf dry matter between $\mathrm{RF} / \mathrm{M} 9$ and $\mathrm{RF} / \mathrm{SH} 40$ or among RF/BC, RF/M9/BC and RF/ SH40/BC (Table 1). Standard rootstock RF/BC also showed significantly greater fine root dry matter than other grafted combinations (Table 1). There were no significant differences in fine root dry matter between RF/M9 and RF/SH40, except in 2012 (Table 1).

The proportion of fruit dry matter to the annual total dry matter of RF/BC was significantly lower than those of RF/M9 and RF/SH40 (Table 1). The proportion of fruit dry matter in $\mathrm{RF} / \mathrm{M} 9 / \mathrm{BC}$ and RF/SH40/BC differed among years (Table 1). The proportion of leaf or fine root dry matter to total dry matter did not significantly differ among all combinations (Table 1). 

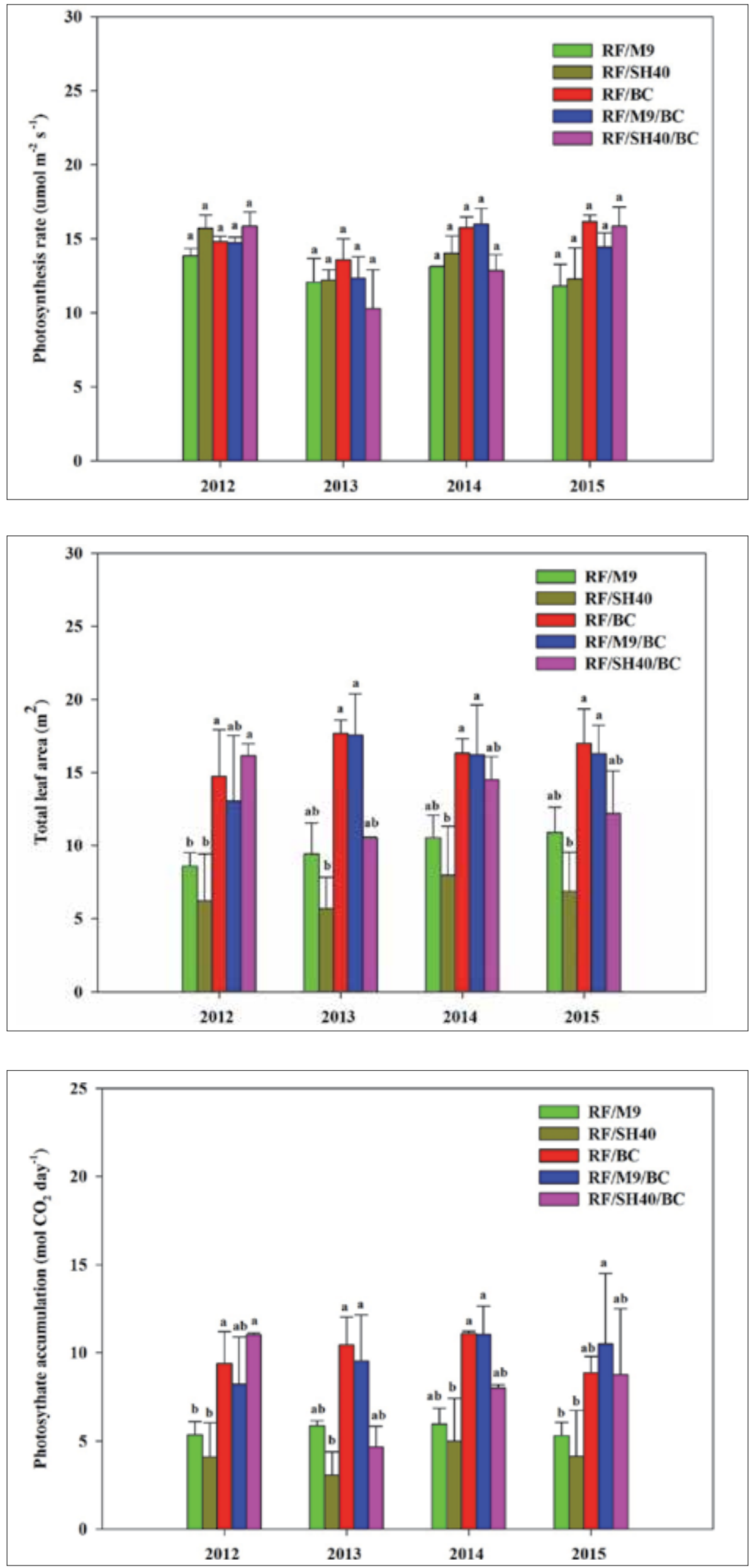

FIGURE 2. Net photosynthesis rate of 'Red Fuji' (RF) trees growing on three rootstocks [M9, SH40 and 'Baleng Crab' (BC)] and two interstems. Data are means $(n=2)$ and the bars represent the standard error; lower case letters indicate significant differences among rootstocks at $P \leq 0.05$.

FIGURE 3. Total leaf area of 'Red Fuji' (RF) trees growing on three rootstocks [M9, SH40 and 'Baleng Crab' (BC)] and two interstems. Data are means $(n=2)$ and the bars represent the standard error; lower case letters indicate significant differences among rootstocks at $P \leq 0.05$.

FIGURE 4. Daily photosynthate accumulation of 'Red Fuji' (RF) trees growing on three rootstocks [M9, SH40 and 'Baleng Crab' (BC)] and two interstems. Daily photosynthate was calculated as the product of leaf area, $\mathrm{Pn}$ rate, and time (12 hours). Data are means $(n=2)$ and the bars represent the standard error; lower case letters indicate significant differences among rootstocks at $P \leq 0.05$. 
TABLE 1. Annual dry matter distribution of 'Red Fuji' (RF) trees growing on three rootstocks [M9, SH40 and 'Baleng Crab' $(B C)]$ and two interstems.

\begin{tabular}{|c|c|c|c|c|c|c|c|c|}
\hline \multirow[b]{2}{*}{ Years } & \multirow[b]{2}{*}{ Treatments } & \multirow{2}{*}{$\begin{array}{l}\text { Annual total } \\
\text { dry matter } \\
(\mathrm{kg})\end{array}$} & \multicolumn{3}{|c|}{ Dry matter (kg) } & \multicolumn{3}{|c|}{ Proportion } \\
\hline & & & Fruit & Leaf & Fine root & $\begin{array}{l}\text { Fruit } \\
(\%)\end{array}$ & $\begin{array}{l}\text { Leaf } \\
(\%)\end{array}$ & $\begin{array}{c}\text { Fine root } \\
(\% 0)\end{array}$ \\
\hline \multirow[t]{5}{*}{2012} & RF/M9 & $15.98 \mathrm{~b}$ & $0.10 \mathrm{~b}$ & $0.58 \mathrm{a}$ & $0.0032 \mathrm{a}$ & $0.60 \mathrm{~b}$ & $3.60 \mathrm{a}$ & $0.20 a$ \\
\hline & RF/SH40 & $12.27 b$ & $0.60 \mathrm{a}$ & $0.54 \mathrm{a}$ & $0.0016 b$ & $4.90 \mathrm{a}$ & $4.41 \mathrm{a}$ & $0.13 a b$ \\
\hline & $\mathrm{RF} / \mathrm{BC}$ & $28.07 \mathrm{ab}$ & $0.00 \mathrm{~b}$ & $1.02 \mathrm{a}$ & $0.0035 a$ & $0.00 \mathrm{c}$ & $3.63 \mathrm{a}$ & $0.12 a b$ \\
\hline & $\mathrm{RF} / \mathrm{M} 9 / \mathrm{BC}$ & $24.58 a b$ & $0.41 \mathrm{a}$ & $0.98 \mathrm{a}$ & $0.0017 b$ & $1.68 b$ & $3.97 \mathrm{a}$ & $0.07 b$ \\
\hline & $\mathrm{RF} / \mathrm{SH} 40 / \mathrm{BC}$ & $32.92 \mathrm{a}$ & $0.69 a$ & $1.25 \mathrm{a}$ & $0.0024 a b$ & $2.09 a b$ & $3.81 \mathrm{a}$ & $0.07 b$ \\
\hline \multirow[t]{5}{*}{2013} & RF/M9 & 14.34 bc & $1.05 \mathrm{ab}$ & $0.62 b c$ & $0.0028 a b$ & $7.30 \mathrm{a}$ & $4.30 \mathrm{a}$ & $0.20 \mathrm{~b}$ \\
\hline & $\mathrm{RF} / \mathrm{SH} 40$ & $8.48 \mathrm{c}$ & $0.72 a b$ & $0.40 \mathrm{c}$ & $0.0037 \mathrm{ab}$ & $8.50 \mathrm{a}$ & $4.70 \mathrm{a}$ & $0.44 a$ \\
\hline & $\mathrm{RF} / \mathrm{BC}$ & $25.6 \mathrm{a}$ & $0.15 b$ & $1.12 \mathrm{a}$ & $0.0066 \mathrm{a}$ & $0.60 \mathrm{~b}$ & $4.40 \mathrm{a}$ & $0.26 \mathrm{~b}$ \\
\hline & $\mathrm{RF} / \mathrm{M} 9 / \mathrm{BC}$ & $22.77 \mathrm{ab}$ & $0.53 \mathrm{ab}$ & $1.07 \mathrm{ab}$ & $0.0023 b$ & $2.30 \mathrm{~b}$ & $4.70 \mathrm{a}$ & $0.10 \mathrm{~b}$ \\
\hline & $\mathrm{RF} / \mathrm{SH} 40 / \mathrm{BC}$ & $15.03 b c$ & $1.77 \mathrm{a}$ & $0.83 a b$ & $0.0023 b$ & $11.80 \mathrm{a}$ & $5.50 a$ & $0.15 b$ \\
\hline \multirow[t]{5}{*}{2014} & RF/M9 & $17.78 \mathrm{ab}$ & $0.19 b$ & $0.69 \mathrm{ab}$ & $0.0032 \mathrm{ab}$ & $1.09 a$ & $3.89 \mathrm{a}$ & $0.18 a$ \\
\hline & RF/SH40 & $14.93 \mathrm{~b}$ & $0.39 a b$ & $0.38 \mathrm{~b}$ & $0.0026 \mathrm{~b}$ & $2.63 \mathrm{a}$ & $2.58 \mathrm{a}$ & $0.18 a$ \\
\hline & $\mathrm{RF} / \mathrm{BC}$ & $33.15 a$ & $0.07 \mathrm{c}$ & $1.02 \mathrm{a}$ & $0.0066 \mathrm{a}$ & $0.20 \mathrm{~b}$ & $3.08 \mathrm{a}$ & $0.20 \mathrm{a}$ \\
\hline & $\mathrm{RF} / \mathrm{M} 9 / \mathrm{BC}$ & $33.01 \mathrm{a}$ & $0.55 a$ & $1.02 \mathrm{a}$ & $0.0028 b$ & $1.66 \mathrm{a}$ & $3.08 \mathrm{a}$ & $0.08 \mathrm{~b}$ \\
\hline & $\mathrm{RF} / \mathrm{SH} 40 / \mathrm{BC}$ & $23.89 a b$ & $0.05 \mathrm{c}$ & $0.79 \mathrm{ab}$ & $0.0046 \mathrm{ab}$ & $0.20 \mathrm{~b}$ & $3.33 a$ & $0.19 a$ \\
\hline \multirow[t]{5}{*}{2015} & RF/M9 & $15.83 \mathrm{~b}$ & $0.38 \mathrm{~b}$ & $0.73 \mathrm{ab}$ & $0.0049 a b$ & $2.38 \mathrm{c}$ & $4.58 \mathrm{a}$ & $0.31 \mathrm{a}$ \\
\hline & RF/SH40 & $12.30 \mathrm{~b}$ & $1.20 \mathrm{a}$ & $0.38 \mathrm{~b}$ & $0.0029 b$ & $9.74 \mathrm{a}$ & $3.08 \mathrm{a}$ & $0.23 a$ \\
\hline & $\mathrm{RF} / \mathrm{BC}$ & $26.56 a b$ & $0.08 \mathrm{c}$ & $1.12 \mathrm{a}$ & $0.0066 \mathrm{a}$ & $0.30 \mathrm{~d}$ & $4.23 a$ & $0.25 \mathrm{a}$ \\
\hline & $\mathrm{RF} / \mathrm{M} 9 / \mathrm{BC}$ & $31.37 \mathrm{a}$ & $0.22 \mathrm{~b}$ & $1.07 \mathrm{a}$ & $0.0035 a b$ & $0.70 \mathrm{~cd}$ & $3.42 \mathrm{a}$ & $0.11 \mathrm{a}$ \\
\hline & $\mathrm{RF} / \mathrm{SH} 40 / \mathrm{BC}$ & $26.17 \mathrm{ab}$ & $1.19 a$ & $0.72 a b$ & $0.0050 a b$ & $4.55 b$ & $2.76 \mathrm{a}$ & $0.19 a$ \\
\hline \multicolumn{9}{|c|}{ ANOVA } \\
\hline \multicolumn{2}{|c|}{ Treatment } & $* * *$ & $* * *$ & $* * *$ & * & *** & NS & ** \\
\hline \multicolumn{2}{|l|}{ Year } & NS & $* * *$ & NS & NS & $* * *$ & NS & * \\
\hline \multicolumn{2}{|c|}{ Treatment $\times$ Year } & NS & $* *$ & NS & NS & $\star * *$ & NS & NS \\
\hline
\end{tabular}

a annual total dry matter was calculated as: the product of leaf area, $\mathrm{Pn}$ and time interval between first and last measurement of photosynthesis rate. In 2012, there was no fruit set in RF/BC, thus its value of fruit dry matter was 0.00 .

Data are means $(n=2)$; different letters in the same column indicate significant differences at $P \leq 0.05$. NS, no significance; ${ }^{*}, P \leq 0.05 ;{ }^{* *}, P \leq 0.01$; ${ }^{* * *}, P \leq 0.001$.

TABLE 2. Vegetative growth of 'Red Fuji' (RF) trees growing on three rootstocks [M9, SH40 and 'Baleng Crab' (BC)] and two interstems in 2015.

\begin{tabular}{lccccc}
\hline Treatments & $\begin{array}{c}\text { Height } \\
(\mathrm{cm})\end{array}$ & $\begin{array}{c}\text { Canopy } \\
\left(\mathrm{m}^{2}\right)\end{array}$ & $\begin{array}{c}\text { RGRS } \\
\left(\mathrm{cm} \mathrm{cm}^{-2} \mathrm{TCSA}\right)\end{array}$ & $\begin{array}{c}\text { Fruit length } \\
(\mathrm{mm})\end{array}$ & $\begin{array}{c}\text { Fruit diameter } \\
(\mathrm{mm})\end{array}$ \\
\hline RF/M9 & $217.0 \mathrm{ab}$ & $7.74 \mathrm{~b}$ & $1.76 \mathrm{a}$ & $66.34 \mathrm{a}$ & $83.3 \mathrm{a}$ \\
RF/SH40 & $195.0 \mathrm{~b}$ & $2.77 \mathrm{~d}$ & $1.89 \mathrm{a}$ & $63.74 \mathrm{a}$ & $79.3 \mathrm{a}$ \\
RF/BC & $262.0 \mathrm{a}$ & $10.79 \mathrm{a}$ & $0.86 \mathrm{c}$ & $52.81 \mathrm{~b}$ & $72.0 \mathrm{~b}$ \\
RF/M9/BC & $252.5 \mathrm{ab}$ & $7.19 \mathrm{bc}$ & $1.16 \mathrm{~b}$ & $52.19 \mathrm{~b}$ & $67.8 \mathrm{c}$ \\
RF/SH40/BC & $204.0 \mathrm{ab}$ & $4.37 \mathrm{~cd}$ & $1.11 \mathrm{bc}$ & $58.75 \mathrm{ab}$ & $71.1 \mathrm{~b}$ \\
\hline
\end{tabular}

a canopy indicates the projection area of tree crown and is calculated as the product of length by width.

${ }^{b}$ RGRS indicates relative growth rate of shoot.

c TCSA indicates trunk cross-sectional area.

Data are means $(n=2)$; different letters in the same column indicate significant differences at $P \leq 0.05$. 
For annual total dry matter, the effect of "treatment" was significant, but the effects of "year" and of "treatment $\times$ year" interaction were not significant (Table 1), suggesting total dry matter was significantly influenced by rootstocks rather than years. The effects of "treatment", "year", and their interaction "treatment $\times$ year" were significant for fruit dry matter and the proportion of fruit dry matter to annual total dry matter (Table 1), indicating that fruit yield varied significantly among rootstocks and among years. The effect of "treatment" was significant for leaf dry matter, but was not significant for the proportion of leaf dry matter to annual total dry matter (Table 1). However, the effects of "year" and "treatment $\times$ year" interaction were not significant for either leaf dry matter or proportion of leaf dry matter to annual total dry matter (Table 1). For fine root dry matter, the effect of "treatment" was significant, but the effects of both "year" and "treatment $\times$ year" were not significant (Table 1 ). The effects of "treatment" and "year" were significant for the proportion of fine root dry matter to total annual dry matter, whereas the "treatment $\times$ year" interaction was not significant (Table 1), suggesting that rootstocks and years significantly influenced fine root production.

\section{Performance of aboveground traits}

At 6 years after planting, the height of RF trees on the standard rootstock $\mathrm{RF} / \mathrm{BC}$ was significantly greater than that of trees on the dwarfing rootstock RF/SH40 (Table 2). There were no significant differences in tree height among RF/M9, $\mathrm{RF} / \mathrm{BC}, \mathrm{RF} / \mathrm{M} 9 / \mathrm{BC}$ and RF/SH40/BC (Table 2). The canopy of RF/BC was also markedly higher than those of RF/M9 and $\mathrm{RF} / \mathrm{SH} 40$, but no significant difference was detected in canopy height between RF/M9 and RF/M9/BC, between RF/M9/ $\mathrm{BC}$ and $\mathrm{RF} / \mathrm{SH} 40 / \mathrm{BC}$, or between $\mathrm{RF} / \mathrm{SH} 40$ and $\mathrm{RF} / \mathrm{SH} 40 / \mathrm{BC}$ (Table 2). The relative growth rate of shoots against trunk cross-sectional area (TCSA) in RF/BC was $0.86 \mathrm{~cm} \mathrm{~cm}^{-2}$ TSCA and was significantly lower than those of RF/M9 and RF/ SH40 (1.76 and $1.89 \mathrm{~cm} \mathrm{~cm}^{-2}$ TSCA, respectively; Table 2). The relative growth of shoots in RF/M9/BC and RF/SH40/ $\mathrm{BC}$ were similar (Table 2) but significantly lower than those in $\mathrm{RF} / \mathrm{M} 9$ and $\mathrm{RF} / \mathrm{SH} 40$; the rate of growth was significantly higher in RF/M9/BC than in RF/BC. These results suggest that although vigorous rootstocks can accelerate the vegetative growth in the scion, they limit the relative growth rate per area (Table 2). The fruit size on dwarfing rootstock RF/ $\mathrm{M} 9$ and RF/SH40 combinations was significantly larger than on the standard rootstock RF/BC combination (Table 2).

\section{Discussion}

Net $\mathrm{Pn}$ is a basic factor in the acquisition of carbon. The published data are inconsistent on whether the Pn of trees on vigorous rootstocks is higher than on dwarfing rootstocks (Schechter et al., 1991; Baugher et al., 1994; Fallahi et al., 1994). In this study, no significant differences in Pn were detected between trees on dwarfing (i.e., RF/M9 and $\mathrm{RF} / \mathrm{SH} 40$ ) and standard (i.e., RF/BC) rootstocks (Figure 2). These results agree with data that indicate that trees on dwarfing rootstocks do not have a significantly higher Pn than those on vigorous rootstocks (Barden et al., 1979). Differences in the total leaf area between vigorous and dwarfing rootstocks may be an important factor in the rate of accumulation of assimilates in apple trees (Atkinson et al., 1999). Rootstocks have a significant effect on the leaf area of shoots (Schechter et al., 1991). The lower rate of accumulation of photosynthates in trees on dwarfing rootstocks is likely due to the reduction in number and size of the leaves (Ishimura et al., 2015). The present work also indicated that total leaf areas of trees on a standard rootstock $(\mathrm{RF} / \mathrm{BC})$ and dwarfing interstem (RF/M9/BC and RF/SH40/BC) were significantly larger than those on the dwarfing rootstocks $\mathrm{RF} / \mathrm{M} 9$ and $\mathrm{RF} /$ SH40 (Figure 3). Consequently, RF/BC, RF/M9/BC and RF/ SH40/BC had a higher daily and annual rate of dry matter accumulation (Figure 4, Table 1). However, the physiological or genetic mechanism that regulates photosynthesis among dwarfing and vigorous rootstocks is still uncertain.

Larger proportions of the annual dry matter were distributed to fruit in trees growing on dwarfing rootstocks/interstems. In addition, the rate of transfer to fruit increases in proportion to the dwarfing ability of the rootstock (Inomata et al., 2005). However, the proportions of dry matter allocated to fine roots or aerial vegetative organs are not consistently or significantly greater in trees on semi-dwarfing or vigorous rootstocks/interstems. The higher absolute volumes of annual dry matter expended on vegetative growth can be attributed to the larger total leaf area. Thus, it is unsurprising that the volumes of tree canopies and roots of trees on vigorous rootstocks/interstems are larger than those on dwarfing rootstocks/interstems (Atkinson et al., 1999; Ma et al., 2013). The use of dwarfing rootstocks results in a better field efficiency compared to trees on vigorous rootstocks (Larsen et al., 1992). Additionally, although vigorous rootstocks accelerate growth of morphological traits of the scion (Table 2), they reduce the yield efficiency and significantly decrease the average fruit size (An et al., 2017). Whether these functional traits (e.g., fruit efficiency and shoot growth) cross-talk and how they affect the allocation of net primary production need to be studied further.

\section{Conclusions}

The analyses here show that net Pn was not associated with a dwarfing effect and that the differences in photosynthate accumulation among dwarfing and standard rootstocks/interstems was mainly due to differences in total leaf area. The genotypes of rootstocks/interstems significantly influenced total dry matter and its allocation; as a consequence, more photosynthates were allocated to fruit in dwarfing rootstock, and more was assigned to leaves in standard rootstocks. These results indicate a potential mechanism that controls photosynthate allocation and helps explain the dwarfing effect of dwarf rootstocks.

\section{Acknowledgments}

This project was supported by the Special Fund for Agro-Scientific Research in the Public Interest (201203075 and 201303093); the Modern Agricultural Industry Technology System (CARS-28); National Key Technology Research and Development Program of the Ministry of Science and Technology of China (2013BAD02B01-4); grants from the Beijing Municipal Education Commission (CEFFPXM2017_014207_000043).

\section{References}

An, H.S., Luo, F.X., Wu, T., Wang, Y., Xu, X.F., Zhang, X.Z, and Han, Z.H. (2017). Dwarfing effect of apple rootstocks is intimately associated with low number of fine roots. HortScience 52, 503-512. https://doi. org/10.21273/HORTSCI11579-16.

Atkinson, C.J., Policarpo, M., Webster, A.D., and Kuden, A.M. (1999). Drought tolerance of apple rootstocks: production and partitioning of dry matter. Plant Soil 206, 223-235. https://doi. org/10.1023/A:1004415817237. 
Barden, J.A., and Ferree, D.C. (1979). Rootstock does not affect net photosynthesis, dark respiration, specific leaf weight, transpiration of apple leaves. J. Am. Soc. Hortic. Sci. 104, 526-528.

Baugher, T.A., Singha, S., Leach, D.W., and Walter, S.P. (1994). Growth, productivity, spur quality, light transmission and net photosynthesis of Golden Delicious apple-trees on 4 rootstocks in 3 training systems. Fruit Var. J. 48, 251-255.

De Silva, H.N., Hall, A.J., Tustin, D.S., and Gandar, P.W. (1999). Analysis of distribution of root length density of apple trees on different dwarfing rootstocks. Ann. Bot. 83, 335-345. https://doi. org/10.1006/anbo.1999.0829.

Drake, S.R., Larsen, F.E., and Higgins, S.S. (1991). Quality and storage of Granny Smith and Greenspur apples on seedling, M26 and MM111 rootstocks. J. Am. Soc. Hort. Sci. 116, 261-264.

Fallahi, E., Simons, B.R., Fellman, J.K., Longstroth, M.A., Colt, W.M., and Ketchie, D.O. (1994). Tree growth and productivity and postharvest fruit-quality in various strains of delicious apple. J. Am. Soc. Hortic. Sci. $119,389-395$

Fallahi, E., Chun, I.J., Neilsen, G.H., and Colt, W.M. (2001). Effects of three rootstocks on photosynthesis, leaf mineral nutrition, and vegetative growth of 'BC-2 Fuji' apple trees. J. Plant Nutr. 24, 827834.

Fallahi, E., Colt, W.M., Fallahi, B., and Chun, I.J. (2002). The importance of apple rootstocks on tree growth, yield, fruit quality, leaf nutrition, and photosynthesis with an emphasis on 'Fuji'. Horttechnology 12, 38-44. https://doi.org/10.1081/PLN-100103776.

Ferree, D.C. (1992). Ten-year summary of the performance of 9 rootstocks in the NC-140 trials. Compact Fruit Tree 25, 5-11.

Ferree, D.C., Cahoon, G.A., Ellis, M.A., Scurlock, D.M., and Johns, G.R. (1996). Influence of eight rootstocks on the performance of 'White Riesling' and 'Cabernet Franc' over five years. Fruit Var. J. 50, 124130.

Hooijdonk, B. van, Woolley, D., Warrington, I., and Tustin, S. (2011). Rootstocks modify scion architecture, endogenous hormones, and root growth of newly grafted 'Royal Gala' apple trees. J. Am. Soc. Hortic. Sci. 136, 93-102.

Hou, C., Ma, L., Luo, F., Wang, Y., Zhang, X., and Han, Z. (2012). Impact of rootstock and interstems on fine root survivorship and seasonal variation in apple. Sci. Hortic. 148, 169-176. https://doi org/10.1016/j.scienta.2012.10.008.

Inomata, Y., Kudo, K., Wada, M., Masuda, T., Bessho, H., and Suzuki, K. (2005). The influence of rootstock on characteristics of tree growth, fruit productivity and dry matter production of 'Maypole' young apple trees. Hortic. Res. 4, 41-46. https://doi.org/10.2503/hrj.4.41.

Ishimura, S., Hirano, E., Hidaka, T., Honsho, C., and Tetsumura, T. (2015). Photosynthetic rates in leaves of 'Hiratanenashi' persimmon trees on 'MKR1' dwarfing rootstock, and vigorating rootstocks, as well as own-rooted trees. Hortic. Res. 14, 255-260. https://doi. org/10.2503/hrj.14.255

Larsen, F.E., Higgins, S.S., and Dolph, C.A. (1992). Rootstock influence over 25 years on yield, yield efficiency and tree growth of cultivars Delicious and Golden Delicious apple (Malus domestica Borkh.) Sci. Hortic. 49, 63-70.https://doi.org/10.1016/0304-4238(92)90143-Z.

Losciale, P., Zibordi, M., Manfrini, L., and Grappadelli, L.C. (2008). Effects of rootstock on pear photosynthetic efficiency. Acta Hortic. 800, 241-248. https://doi.org/10.17660/ActaHortic.2008.800.28.

Ma, L., Hou, C.W., Zhang, X.Z., Li, H.L., Han, D.G., Wang, Y., and Han, Z.H. (2013). Seasonal growth and spatial distribution of apple tree roots on different rootstocks or interstems. J. Am. Soc. Hortic. Sci. $138,79-87$.

Neilsen, G.H., Parchomchuk, P., Beard, R., and Neilsen, D. (1997). Irrigation frequency and quantity affect root and top growth of fertigated 'McIntosh' apple on M.9, M.26 and M.7 rootstock. Can. J. Plant Sci. 77, 133-139. https://doi.org/10.4141/P96-095.

Preston, A.P. (1968). Scion weight and cropping of Cox's Orange Pippin and Jonathan apples on some Mailing and Mailing-Merton rootstock. Rpt. E. Mailing Res. Sta. 1967, 98-102.

Rieger, M. (1992). Growth, gas exchange, water uptake, and drought response of seedling and cutting-propagated peach and citrus rootstock. J. Amer. Soc. Hortic. Sci. 117, 834-840.

Robinson, T.L., Fazio, G., Aldwinckle, H.S., Hoying, S.A., and Russo, N. (2006). Field performance of Geneva apple rootstocks in the Eastern USA. Sodininkyste ir Darzininkyste 25, 181-191.

Samad, A., McNeil, D.L., and Khan, Z.U. (1999). Effect of interstock bridge grafting (M9 dwarfing rootstock and same cultivar cutting) on vegetative growth, reproductive growth and carbohydrate composition of mature apple trees. Sci. Hortic. 79, 23-38. https:// doi.org/10.1016/S0304-4238(98)00179-4.

Schechter, I., Elfving, D.C., and Proctor, J.T.A. (1991). Apple tree canopy development and photosynthesis as affected by rootstock. Can. J. Bot. 69, 295-300. https://doi.org/10.1139/b91-039.

Strong, D., and Azarenko, A.N. (2000). Altered dry matter partitioning of 'Starkspur Supreme Delicious' apple trees by nine rootstocks. Fruit Var. J. 54, 11-17.

Stutte, G.W., Baugher, T.A., Walter, S.P., Leach, D.W., Glenn, D.M., and Tworkoski, T.J. (1994). Rootstock and training system affect drymatter and carbohydrate distribution in Golden Delicious apple trees. J. Am. Soc. Hortic. Sci. 119, 492-497.

Webster, A.D. (1995). Rootstock and interstock effects on deciduous fruit tree vigour, precocity, and yield productivity. New Zeal. J. Crop Hortic. Sci. 23, 373-382. https://doi.org/10.1080/01140671.1995. 9513913

Wu, T., Wang, Y., Yu, C.J., Chiarawipa, R., Zhang, X.Z., Han, Z.H., and Wu, L.H. (2012). Carbon sequestration by fruit trees - Chinese apple orchards as an example. Plos One 7, 69. https://doi.org/10.1371/ journal.pone.0038883.

Yao, S.R., Merwin, I.A., and Brown, M.G. (2006). Root dynamics of apple rootstocks in a replanted orchard. HortScience 41,1149-1155.

Received: Jan. 12, 2017

Accepted: Jun. 28, 2017

Addresses of authors:

Haishan An, Feixiong Luo, Ting Wu, Yi Wang, Xuefeng Xu, Xinzhong Zhang and Zhenhai Han*

Institute for Horticultural Plants, College of Horticulture, China Agricultural University, No. 2 Yuanmingyuan West Road, Haidian District, Beijing 100193, P.R. China

*Corresponding author; E-mail: rschan@cau.edu.cn

Tel.: +8610 62732467; Fax: +861062734391 